\title{
Construções dramatúrgicas nas criações de artistas independentes da dança contemporânea
}

\author{
Vanessa Freitas de Paiva Macedo \\ Doutorado em Artes Cênicas da Universidade de São Paulo - projeto em andamento \\ Teoria e Prática do Teatro \\ Orientadora: Sayonara Sousa Pereira \\ Coreógrafa, diretora e intérprete da Cia Fragmento de Dança
}

Resumo: Este projeto propõe discutir dramaturgia em seu conceito ampliado, ou seja, discuti-la considerando a construção de sentidos proposta por uma obra e o processo criativo que a envolve. $\mathrm{O}$ recorte do tema se dará no cenário da dança independente contemporânea, situada no Brasil. O estudo analisará recorrências e diferenças existentes nas poéticas desses artistas independentes, incluindo o trabalho artístico da autora. $\mathrm{O}$ conceito de processo criativo tem como referência os estudos da crítica genética sistematizados pela pesquisadora Cecilia Salles ${ }^{\mathrm{i}}$, principalmente, no que tange ao seu entendimento de investigá-lo como uma construção em rede. Esses conceitos são incorporados à pesquisa sobre dramaturgia por se entender que ela caminha junto ao processo criativo da obra.

Palavras-chaves: Dramaturgia, processo de criação, dança contemporânea, artistas independentes

Title:Dramaturgical constructions in the creations of independent artists of contemporary dance Abstract: This project proposes to discuss the dramaturgy in its broadest concept, in other words, to discuss dramaturgy considering the construction of meanings proposed by an artwork and its creative process. The clipping of the issue will be the scene of independent contemporary dance in Brazil. The study will examine the differences and the recurrences in artworks from these artists, including the author. The concept of creative process has as reference the fundamentals of critical genetic systematized by Cecilia Salles, especially regarding to her understanding of investigating it as a construction in network. These concepts are incorporated into research on dramaturgy by understanding that it walks next to the creation process.

Keywords: dramaturgy, creative process, contemporary dance, independent artists

Título:Construcciones dramatúrgicas en las creaciones de artistas independientes en la danza contemporánea

Resumen: Este proyecto tiene como objetivo discutir la dramaturgia en su concepto más amplio, dar a conocer lo que se está considerando en la construcción del sentido que propone un proceso de trabajo y creatividad implicando el recorte de la emisión de la escena independiente con danza contemporánea, desarrollada en Brasil. El estudio analiza las recurrencias y diferencias existentes en la poética de estos artistas independientes, incluyendo las ilustraciones de la autora. El concepto del proceso creativo hace referencia a los estudios sistemáticos de la crítica genética por la investigadora Cecilia Salles, sobre todo cuando se trata de su comprensión de investigar como una construcción en la red. Estos conceptos se incorporan a la investigación sobre la dramaturgia al entender lo que acontece con el proceso creativo de la obra.

Palabras clave: Dramaturgia, proceso creativo, danza contemporánea, artistas independientes

\section{Introdução}

Este projeto propõe pensar dramaturgia em seu sentido ampliado, ou seja, descolada do entendimento clássico que restringia o seu significado ao texto ou à composição de uma peça 
teatral. A ideia é relacioná-la com as características de um pensamento em rede, multifocal, não linear, e que caminha junto ao processo de criação.

Por acreditar que ela passa pela construção de sentidos da obra e essa construção é materializada na ação, ressalta-se a definição dada por Jean-Marc Adolphe ${ }^{\mathrm{ii}}$ de que "dramaturgia não é a resolução de um elemento dentro do outro (o sentido dentro da ação ou o inverso), mas a dialética que se estabelece entre ação e sentido" (1997, n.p.).

Entendendo a dramaturgia em dança como a tessitura da obra, que passa pela forma como é pensado o corpo, desenhado o movimento e construída a cena, percebe-se que seu diálogo com o percurso criativo é constante, quase simbiótico. A dramaturgia, portanto, não é anterior ao início do processo de criação e nem é introduzida depois. Mesmo contaminada de todas as escolhas e experiências estéticas do criador, ela também é construída, sofrendo todos os desvios e se alimentando dos acasos, riscos e imprevisões presentes no trajeto criativo.

Percebe-se, considerando o seu caráter processual, que a dramaturgia agrega características muito semelhantes às dadas ao processo de criação, segundo os estudos da crítica genética, tais como: Dinamicidade, incerteza, mutabilidade, inacabamento, falibilidade. (SALLES, 2006).

Essas características permitem encontrar generalizações que correspondem ao fazer artístico na dança contemporânea como um todo e, ao mesmo tempo, possibilita investigar singularidades de cada processo criativo. Com isso, desvela-se recorrências e particularidades nos modos como se aborda os processos de criação, e entende-se que esses modos diversos resultam em produções cênicas diversas na atualidade. Considera-se também que as escolhas de abordagens nesses percursos criativos sejam afetadas pela forma como os artistas estão organizados (trabalhos solos, em grupos, em coletivos, etc.), e pela forma que produzem suas criações. Disso decorrem modos de existir, e são esses modos que interessam esta pesquisa, pois revelam uma gama de possibilidades de se pensar a dramaturgia em dança.

É considerando o pensamento de Salles que esta pesquisa entende o conceito de processo de criação e o aproxima da dramaturgia de uma obra. A autora o define como:

Percurso sensível e intelectual de objetos artísticos, científicos e midiáticos que pode ser descrito, numa perspectiva semiótica, como um movimento falível com tendências, sustentado pela lógica da incerteza, englobando a intervenção do acaso e abrindo espaço para a introdução de ideias novas. Um processo contínuo sem um ponto inicial, nem final. Um percurso de construção inserido no espaço e tempo da criação, que inevitavelmente afetam o $\operatorname{artista}^{\text {iii }}$.

Importante ressaltar, no entanto, que foi por meio do contato da pesquisadora com o dossier Danse et dramaturgie, publicado na revista belga Nouvelle de Danse, que se instaurou o interesse 
pelo tema. Neste dossiê, dramaturgos, pesquisadores, críticos e artistas discutem dramaturgia em dança a partir do fim dos anos 80 e, apesar de não ser um documento recente, como exige uma pesquisa que discute arte contemporânea, ainda é uma referência atual às questões que esta pesquisa instaura, pois reúne nomes importantes, e que fundamentam o seu estudo teórico, como Marianne Van Kerkhoven $^{\text {iv }}$. O projeto propõe construir um documento similar ao dossiê citado, aqui reunindo artistas brasileiros independentes. Ao discutir questões sobre dramaturgia e processos criativos, agregará reflexões de criadores que têm uma prática intensa, mas que talvez não se debrucem em analisá-la sob este prisma.

Os artistas investigados neste projeto são os chamados independentes, e se identificam por uma forma específica de pensar, propor e desenvolver seus projetos poéticos, a partir de uma dança de pesquisa que se consolida num trabalho de linguagem autoral. A fim de delimitar um espaço que de fato dialogue com as questões propostas, atender-se-á aos seguintes critérios: Ser um artista independente que desenvolve seu trabalho num núcleo de pesquisa em dança contemporânea; estar pesquisando continuamente e ter atuação reconhecida na área há pelo menos 10 anos; não estar vinculado a nenhum corpo estável, Cia. com estruturada semelhante ou ter algum tipo de compromisso que vincule suas criações a exigências políticas ou mercadológicas.

Não se trata de escolher artistas para estudo de casos de processos criativos específicos, e sim reunir nomes de referência nacional, contemplando a diversidade nos modos como se pensa a dramaturgia em dança, e nas formas como a obra se apresenta cenicamente. Acreditando que muitos desses processos criativos se assemelham, ou seja, apesar de peculiares, aproximam-se em seus modos de abordagens, esta pesquisa encontrará, em alguns artistas do cenário da dança nacional, uma referência que representa um grupo maior de outros artistas, também independentes. Aqui são indicados dois nomes que já começaram a ser investigados: Sandro Borelli ${ }^{\mathrm{v}} \mathrm{e}$ Alejandro Ahmed ${ }^{\mathrm{vi}}$. A escolha se deu não somente porque ambos preenchem os critérios que esta pesquisa definiu, mas principalmente porque são considerados referência no cenário da dança contemporânea nacional, pela reconhecida e diferenciada escritura autoral de suas obras.

\section{Objetivos}

Objetivo Geral:

O objetivo deste projeto é investigar dramaturgia e relacioná-la às diferentes formas de abordagens existentes nos processos criativos e nas produções em dança na contemporaneidade.

Objetivos específicos: 
1 - Analisar a dramaturgia em dança a partir do estudo da transformação e ampliação do seu conceito ao longo da história;

2 - Construir conceitos sobre dramaturgia em dança, documentando ideias, pensamentos e metodologias de artistas e grupos independentes do Brasil.

3 - Discutir, a partir da dramaturgia da obra, a diversidade existente nas formas processuais e nas resoluções cênicas da atualidade, considerando os artistas independentes investigados e o trabalho artístico da autora, com o núcleo Cia Fragmento de Dança ${ }^{\text {vii }}$.

\section{Metodologia}

A investigação divide-se entre a pesquisa realizada com os artistas independentes e aquela realizada com a Cia Fragmento de Dança. Ressalta-se que não se trata de estudo de casos, o que demandaria um aprofundamento em trabalhos específicos, e sim de um estudo de variadas formas de abordagens nas construções dramatúrgicas, considerando a reflexão que o próprio criador tem do seu processo artístico. Reflexão esta que passa, obviamente, pela observação e interpretação da autora que, além de coletar dados, busca, a partir deles, construir conceitos sobre o tema.

A pesquisa com outros artistas considera as seguintes estratégias:

1 - Mapeamento dos trabalhos artísticos, dentro do recorte proposto, o que inicialmente tem sido feito por meio da presença da pesquisadora em espetáculos de dança que acontecem na cidade de São Paulo. Acredita-se que este primeiro contato demonstre uma diversidade de abordagens cênicas, consequentes da diversidade existente nos processos criativos/dramatúrgicos. A autora, portanto, observa como o criador desenha os corpos coreograficamente no espaço; se faz uso ou não da improvisação; se apresenta uma estrutura fechada de movimentos; se há uma hierarquia entre os elementos da cena; se a plateia é observadora/ receptora ou se compartilha o espetáculo enquanto experiência, entre outras relações.

2 - Seleção e primeiro contato com pesquisadores especialistas no assunto e com cerca de 30 artistas, dentre os que tiveram seus trabalhos assistidos, para uma entrevista semiestruturada, na qual será proposto um diálogo sobre "a forma como abordam seus processos criativos e o que pensam sobre dramaturgia em dança”. A pesquisa, em seu estágio atual, entrevistou 7 artistas: Sandro Borelli (São Paulo-SP), Alejandro Ahmed (Florianópolis-SC), Luis Ferron (São Paulo-SP), Marcelo Evelin (Teresina-PI), Ricardo Iazzetta (São Paulo-SP), Cláudia de Souza (São Paulo-SP) e Rui Moreira (Belo Horizonte -MG ). 
3 - Aprofundamento do tema, inicialmente, a partir de dois nomes: Alejandro Ahmed e Sandro Borelli, por meio de entrevistas e acompanhamento de alguns processos e resultados cênicos.

No que se refere à Cia Fragmento de Dança, a prática com este núcleo artístico se dará por meio de propostas criativas que instaurem questões sobre o tema, como por exemplo, a discussão sobre o quanto é afetada a dramaturgia de um espetáculo quando a mesma coreografia é executada por intérpretes diferentes. No momento atual desta pesquisa, tem-se experimentado três artistas com formações diversas em dança para que, a partir de um mesmo material coreográfico, desenvolvam encenações próprias. Com isso observar-se-á de que forma a dramaturgia da criação é afetada pelo modo como cada intérprete executa a coreografia e pelas outras relações que propõe com o espaço, a música e o figurino (elementos que serão concebidos individualmente pelos artistas participantes do experimento).

\section{Considerações finais}

A dramaturgia em dança é assunto cada vez mais recorrente entre diretores, coreógrafos, bailarinos e pesquisadores da atualidade. A pesquisa acadêmica, entendendo a dança como produtora de conhecimento que discute e reflete sobre questões do seu domínio específico, possibilita a investigação e registro de diferentes percepções sobre o tema, contribuindo para o seu entendimento, ainda carente de sistematizações. Para tanto, faz-se necessário construir conceitos acerca de dramaturgia e processo de criação em dança para, diante disso, analisar e encontrar dados sobre a diversidade da produção de dança contemporânea, considerando os modos como os artistas estão se organizando, as suas formas de abordagens criativas e as implicações disso nas construções dramatúrgicas de seus produtos artísticos.

\section{Referência bibliográfica}

ADOLPHE, J. M; KERHOVE, M. V; PICKELS, Antoine. Dossier Danse et Dramaturgie, in Nouvelles de Danse. Contredanse, 31. Bruxelles, 1997.

NAVAS, Cássia. Escritura e Dramaturgia. Anais do II Congresso da Associação Brasileira de Pesquisa e Pós-graduação em Artes Cênicas, Salvador, ABRACE, 2001.

Congresso ABRACE/UFBA, 2003.

Dança: escritura análise e dramaturgia. Salvador: anais do III

PAIS, Ana; SAADI, Fátima; SOTER, Silvia; ROCHA, Tereza. Temas para a Dança Brasileira. Organização Sigrid Nora. São Paulo, Edição Sesc SP, 2010.

SALLES, Cecília Almeida. Gesto Inacabado Processo de Criação Artística. São Paulo: Annablume, 1998.

2006. Redes da Criação. Construção da Obra de Arte. São Paulo: Horizonte, 
PAVIS, Patrice. Dicionário de Teatro. São Paulo: Perspectiva, 2005.

' Crítica genética é a investigação da obra de arte tendo como foco a sua construção. A princípio voltava-se ao estudo de casos na literatura. Cecília Almeida Salles é uma das principais pesquisadoras no Brasil que aplicou a crítica genética ao estudo de outras mídias. O enfoque desta pesquisadora volta-se ao processo de criação, independentemente da linguagem artística estudada. Propõe encontrar generalizações que correspondem ao fazer artístico como um todo, e singularidades, em cada caso estudado.

ii Jornalista, redator-chefe da revista francesa "Mouvement", especializou-se em crítica de dança e teatro e foi conselheiro artístico do Teatro da Bastilha de Paris de 1994 a 2002.

iii Conceito dado a processo de criação. Disponível em www.redesdacriação.org.br, site que reúne um vocabulário que trata especificamente de todos os conceitos que a crítica genética de Cecilia Salles aborda.

${ }^{\text {iv }}$ Dramaturga do Kaaither, trabalhou com diversos coreógrafos, entre eles Anne Teresa De Keersmaeker, fundadora da Cia. de dança ROSAS, de Bruxelas-Bélgica.

${ }^{\vee}$ Diretor e coreógrafo da Cia Borelli de Dança, um dos núcleos artísticos de maior atuação no estado de São Paulo, criado no ano de 1997. Seus trabalhos são reconhecidos por uma densidade cênica singular, inspirada em temas que tratam dos conflitos sócio políticos do homem contemporâneo.

${ }^{v i}$ Diretor e coreógrafo do Grupo Cena 11, de Florianópolis -SC, desde 1992. Uma das características de seus trabalhos é o experimento entre dança e tecnologia. Sua pesquisa está em constante diálogo com acadêmicos e busca construir conceitos, dentre os quais está a relação do corpo com o ambiente.

${ }^{\text {vii }}$ Núcleo artístico no qual a pesquisadora é coreógrafa, diretora e intérprete que iniciou suas atividades de pesquisa e criação em dança contemporânea, no ano de 2002, na cidade de São Paulo. 